\title{
Te Vaerua Community Rehabilitation Service: a Participation Action Research study of Community Based Rehabilitation in the cook Islands
}

\author{
Rebecca Washbourn BPhty, PGDipRehab \\ Physiotherapist, Christchurch
}

William M. M. Levack PhD, MHealSc (Rehabilitation), BPhty

Associate Dean Research and Senior Lecturer in Rehabilitation, Rehabilitation Teaching and Research Unit, Department of Medicine, University of Otago Wellington, New Zealand

Fiona Graham PhD, B OccTher

Senior Lecturer in Rehabilitation, Rehabilitation Teaching and Research Unit, Department of Medicine, University of Otago Wellington, New Zealand

Nandika Currey PGDip (Public Health), BSC (Psych)

Associate Dean Pacific and Doctoral Fellow (Mental Health), Dean's Department, University of Otago Wellington, New Zealand

\section{ABSTRACT}

Community based rehabilitation (CBR) is a World Health Organisation initiative to support people with disabilities to attain maximal life participation through locally based programmes. Te Vaerua Community Rehabilitation Team (Te Vaerua) is a provider of CBR in the Cook Islands. This study used a Participatory Action Research (PAR) framework to explore cultural values, motivations for and provision of rehabilitation by Te Vaerua in the Cook Islands. Data was collected through focus groups, interviews, participant observation, and an emergent process of action cycles with local rehabilitation stakeholders. Three key themes were identified: 1) rehabilitation is available, 2) rehabilitation has heart, and 3) rehabilitation gives hope. These themes have an overarching concept of 'ko te iti tangata te mea maata' - that people are the most important thing. Rehabilitation was seen as central to broader social objectives to strengthen families, empower Cook Islands citizens, support people to remain in the Cook Islands, and to provide opportunities for people to give back to their communities. The study concluded that strong relationships between providers and the local community are essential to successfully implement both PAR and CBR.

Washbourn R, Levack W, Graham F, Currey N (2016) Te Vaerua Community Rehabilitation Service: a Participation Action Research study of Community Based Rehabilitation in the Cook Islands. New Zealand Journal of Physiotherapy 44(2): 97-104. doi: 10.15619/NZJPI44.2.05.

Key words: Rehabilitation, Community-based participatory research, Polynesia, Cook Islands, Pacific, Action research

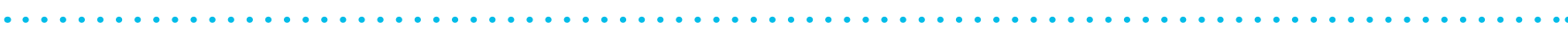

\section{INTRODUCTION}

Community Based Rehabilitation (CBR) was initially developed by the World Health Organisation in the 1970s as a strategy to provide better rehabilitation services to people with disabilities by drawing on local community knowledge and resources (Khasnabis et al 2010). CBR typically takes a rights based approach to promote access to healthcare, education and community participation (Grandisson et al 2016, Khasnabis et al 2010) and is underlined by conceptual frameworks such as the social model of disability and the International Classification of Functioning, Disability and Health (ICF) (Biggeri et al 2014).

Development initiatives in newly industrialised countries have historically been initiated by international organisations working outside of the communities they aim to serve (Khasnabis et al 2010). These 'top down' programmes have been criticised in the past for their limited impact, largely due to failing to address local needs in a manner consistent with local values or sustainable by local resources (Kuipers and Allen 2004, O'Toole 1987, Shakespeare and Officer 2014). In contrast, CBR is an example of a 'grass roots' or 'bottom-up' approach that requires a combined effort of individuals with disabilities, disability advocacy groups, governments, and service agencies within a country being actively involved at all stages of programme development, implementation and monitoring (Biggeri et al 2014, lemmi et al 2015, International Labour Organisation et al 2004, Khasnabis et al 2010). CBR draws on a community's knowledge to directly inform the development of new services or initiatives. As a result CBR should result in sustainable and culturally appropriate services and supports for people with disabilities (Deepak et al 2014, lemmi et al 2015, Yuenwah 2012).

Nevertheless, CBR is not without challenges. The skills and resources needed to run a CBR project may be limited, resulting in overseas 'experts' being recruited to fill perceived gaps (Mpofu 2001, Thomas and Thomas 1999). There is also limited evidence supporting the effectiveness of CBR, most of which is case-study based - focusing on individual projects in specific places (eg Balasubramanian et al 2012, Biggeri et al 2014, Nuri et al 2012). Generalised or long-term benefits of CBR have yet to be demonstrated (Bowers et al 2015, Madden et al 2013). 
Generation of such evidence is challenging due to the diversity of contexts and situations in which people from different nations live and function. Concepts of health are culturally mediated (Durie 1994, Fitzgerald 1992, Hughes 2008) adding to the difficulty with comparing or combining evaluations of CBR projects.

The study described in this paper arose following the experiences of the first author, a New Zealand European (RW) working as a physiotherapist in a rehabilitation service for a Pacific Island nation, specifically Te Vaerua Community Rehabilitation Inc. (aka. Te Vaerua) in the Cook Islands, and her questioning of differences in understandings of rehabilitation. Te Vaerua was first established in 2007 and is based in Rarotonga. It operates within the concepts and philosophy of CBR, providing rehabilitation and support to people with disabilities throughout the Cook Islands. The Cook Islands is a Pacific Island nation comprised of 15 small, isolated islands spread across a vast ocean area, with a population of 17,800 (Ministry of Finance and Economic Management 2012). The Cook Islands has a protectorate agreement with New Zealand meaning that Cook Islands residents are eligible for Aucklandbased tertiary medical services, including rehabilitation. Te Vaerua works alongside existing primary and secondary health services providing physiotherapy, adaptive equipment, home visits and clinic-based rehabilitation. To date it has employed "Western" physiotherapists, mainly from New Zealand. The aim of this research was to explore how rehabilitation was valued and should be provided in a Cook Islands setting, and thus to support Te Vaerua to further develop their services. The research also aimed to generate guidance for "Western" therapists working in the region regarding how rehabilitation should be conceptualised and provided.

\section{METHOD}

\section{Study design}

Participatory action research (PAR) is a cyclical process of data collection, analysis, implementation and re-evaluation that occurs within a democratic framework of involvement. PAR holds that practical solutions, changes or 'actions' that benefit study participants are an integral part of the research process (Mclntyre 2008).

PAR involves a progression of choices which influence direction, processes and outcome (Bradbury and Reason 2008). These choices are based on a transparent process of collaborative decision making with study participants, which emerge throughout the research process (Maiter et al 2008, McTaggart 1991). PAR is a valuable approach for cross cultural projects as it allows the community itself to identify and define all aspects of the research process. This embeds the research within the participants' cultural context and understandings, ensuring the research is meaningful to the participants (Maiter et al 2008, McTaggart 1991, Roberts 2013). Within PAR the researcher is equally a participant, and needs to be self-reflexive about the influence and interpretation that their positioning effects (Mclntyre 2008, Somekh 2005). This study holds a constructivist paradigm, which includes the view that there are multiple social realities and gives context for cultural safety to be incorporated into the methodology.

\section{Initial consultation}

During initial consultation with the first author (RW), the Te Vaerua board members indicated their wish to use research to improve their provision of rehabilitation services in the Cook Islands. A preliminary research proposal was submitted to the board via email in January 2013, and the proposal was reviewed and altered by the board prior to development of the method or submission of ethical review of the study. A timeframe for planned data collection was agreed during which time the primary author (RW) was to also provide physiotherapy services for Te Vaerua. Prior to the start of the research the study was reviewed and approved by the University of Otago Rehabilitation Human Ethics Committee (13/185) and the Health Research Committee of the Cook Islands National Research Council.

Participant recruitment and initial study set up PAR requires engagement with local people to create meaningful research which directly benefits the participants' community. Unlike more traditional forms of research, decisions regarding who should be involved in a study and the direction the study should take are directed far more by the study participants themselves than by the researcher (Frisby et al 2005, McIntyre 2008). In this study, the community in question was Te Vaerua, which included both those who provided and those who benefited from the service. Initially, participants were recruited by self-selection, with board members offered the opportunity to be part of the research process. All participants were given an information sheet and a memorandum of understanding as part of the consent process. Seven board members attended an initial meeting. These current board members included men and women, Cook Islanders and Europeans resident in the Cook Islands with differing lengths of time involved in the development and implementation of Te Vaerua.

Through action cycle meetings, other participants were identified who could contribute to discussions of expectations and understandings of rehabilitation - ie snowball sampling (Sadler et al 2010). These participants included funders from the Cook Islands Ministry of Internal Affairs and rehabilitation staff members. Identified individuals were approached to seek their opinions and involvement. In addition to the board members, two participants representing service funders and four participants representing health providers (an occupational therapist, an equipment maintenance manager, a family support volunteer, and a physiotherapist) were recruited. The researcher was also embedded in the health provider participant group as a second clinical physiotherapist at the time of data collection. During one early meeting with the board consideration was also given to recruiting patients and community members for the study, but these connections needed to be mediated by Te Vaerua and did not eventuate.

\section{Data collection}

Following the PAR action cycle and the preference of the participants involved, data collection evolved over a three month period to include focus groups, semi structured interviews and ethnographic observations of board meetings as well as informal dialogue with therapists and patients (see Table 1). 
Table 1: Summary of participant groups and types of data collected

\begin{tabular}{llll}
\hline Participants & Board members $(\mathrm{n}=7)$ & Funders $(\mathrm{n}=2)$ & Therapists $(\mathrm{n}=4)$ \\
\hline Data collected & Board meetings observed (x3 meeting) & $\begin{array}{l}\text { Interview } \\
(\times 1 \text { meeting with funders })\end{array}$ & Focus groups (x3 meetings) \\
& Focus groups (x2 meetings) & \\
& $\begin{array}{l}\text { Interviews (with 4 individuals over 5 } \\
\text { interviews) }\end{array}$ &
\end{tabular}

Three types of study data were gathered: 1) audio-recordings and transcriptions of meetings and interviews, 2) memberchecked summary sheets of interviews and meetings, and 3) personal observations and reflections recorded in written and audio journals (see Figure 1). The researcher diary also gave opportunity for reflexivity, and provided context for discussion of cultural influences on data interpretation with the coinvestigators and study participants. In addition, use of a (non-participant) Cook Islands Māori physiotherapist as a 'critical friend' (Adams-Smith 2002) gave further perspective valuable to researcher positioning.

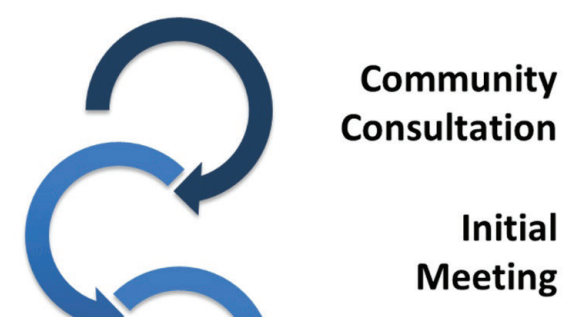

Focus Group

\section{Board Meeting}

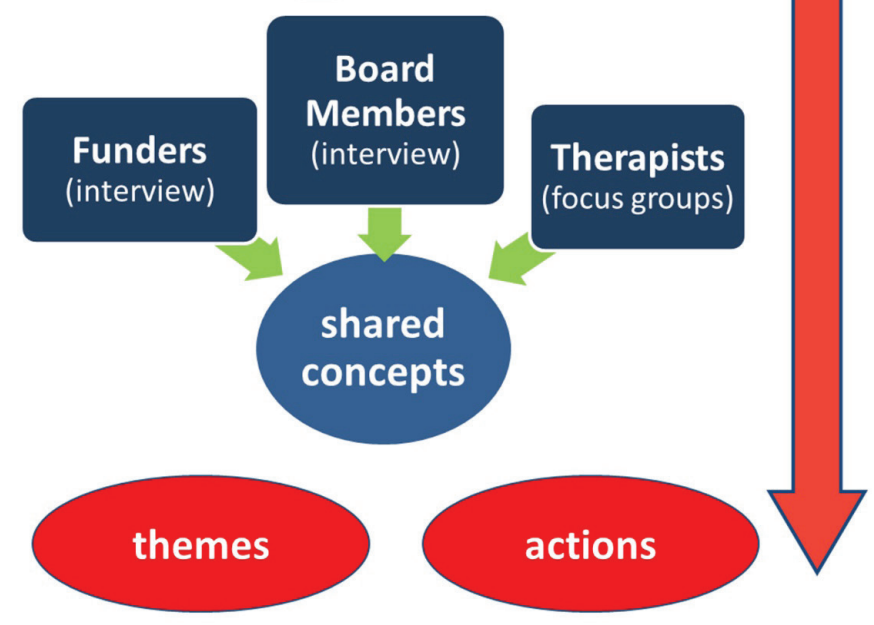

Figure 1: Overview of participant recruitment and data collection process

All discussions, focus groups, and interviews centred on key questions that were identified in the initial meeting with the Te Vaerua Board members. These were:

- What is the ideal rehabilitation service for Te Vaerua?
- What gaps exist in the current service?

- What are Te Vaerua's core values and services, and what things are most important?

All data collection (meetings and interviews) was conducted in English. All participants were fluent in English. Te Vaerua, board meetings and clinical meetings were normally undertaken predominately in English.

Data analysis

Analysis consisted of thematic analysis of concepts arising from the data (Spencer et al 2003). PAR involves ongoing, iterative cycles of investigating, actions, outcomes, and learnings. Analysis is shared with participants during the action cycle as part of the process of reconsideration and change. During data analysis each audio-recording was listened to alongside the verified summary sheet and transcription, with initial coding conducted by the first author (RW). Peer-coding and discussion of the interview transcripts by other members of the research team (WL, FG, and NC) was used to enrich the analysis and strengthen its trustworthiness. Initial themes emerging from the transcripts were documented and discussed with participants to ensure transparency and integrity of thematic extraction. These discussions with participants also helped the process of data analysis remain consistent with the objective of PAR, which is in part about partnership in knowledge creation. However, while the participants in this study were involved in discussion of emerging themes, they chose not to be involved specifically in data coding. Instead, preliminary findings were presented back to the participant group at a board meeting for verification, where they were judged to be representative of the community's views.

\section{RESULTS}

\section{Overview of findings}

The central concept that emerged from this study was the Cook Islands phrase 'Ko te iti tangata te mea maata', which translates as 'people are the most important thing'. This concept was viewed as key to all service provision and service objectives of Te Vaerua, and linked the wellbeing of the community to the wellbeing of each individual within it.

All participants felt that rehabilitation was important, and board members were passionate about having a rehabilitation service on the islands. Te Vaerua members were involved in the organisation primarily to fulfil a drive to provide a service to the community rather than as having a specific interest in health or rehabilitative care per se. None expressed a clinical perspective on what rehabilitation should be like or what specific services should be offered. Rather, a vision of what 
successful rehabilitation would achieve within the community was expressed, and formulation of what and how clinical service would be delivered was left to the discretion and expertise of the employed therapists - the overseas 'experts'.

At the end of the day, the people driving it, you know, there is a purpose, and the purpose is always the people. (Board Member, P1)

Participants expressed the view, which they grounded in a Christian worldview, that each person is unique; worthy and valued despite disability or status. They also expressed a shared view of their responsibility to the community in easing the burden of others. An interconnectedness of people was evident throughout these discussions. Provision of services therefore needed to align with the needs of people on the Cook Islands, and in particular, people who were less privileged or required assistance.

For me that is what Te Vaerua is. Te Vaerua's purpose is to make Cook Islanders' lives better (Board Member, P2).

Three key themes emerged from this central concept: 1) that rehabilitation be available, ie locally present, accessible, and pragmatically useful for the people who require it, 2) that rehabilitation have 'heart', ie be built on interpersonal relationships and involve a shared responsibility between individuals in a community, expressed as a cultural expectation of giving and providing support, and 3) that rehabilitation provide hope by offering the possibility of a better life (see Table 2).

\section{Rehabilitation is available}

The concept of the availability of rehabilitation on Rarotonga was closely associated with family wellbeing and with the accessibility of services for members of the community. Furthermore, for rehabilitation services to be available, they had to be locally-based, visible, practical, and strategic.

It emerged that following a major medical event, it was common for families to take their family member to New Zealand for rehabilitation. Whole families often then emigrated or were split between countries for the duration of medical need:

What happens is Te Vaerua enabling Cook Islanders to get treatment at home, here. It is enabling families to stay together because in the past, if, say my dad had a stroke, and then he had to go to NZ to get the treatment that he needed, then, I would have to take my dad there, I would have to take my family there, you know, we would leave and then we would never come home (Board Member, P1).

Emigration created a burden on family members - both those remaining in the islands, and those in New Zealand who were expected to support the visiting patients. At a community level, the economic burden of serious illness and disability also therefore included the loss of working families from the Cook Islands. As a result, the importance of rehabilitation being available locally was more about families and communities staying together and about minimising family stress than it was about providing any particular therapy.
Strategically, associated with the availability of rehabilitation was an awareness of the importance of visibility of services to health funders, patients, the Ministry of Health, and the community as a whole. It was understood that Te Vaerua had to be seen as successful by external people and parties in their wider community in order to gain funding, referrals and the community support required to function effectively. Visibility was enhanced by the use of Te Vaerua's clinic as a physical 'place' on the island, which gave the service a physical presence on the Cook Islands and provided a flagship for the good work they did.

Another form of visibility was apparent in the prescribing and issuing of adaptive equipment, which was viewed as tangible evidence of usefulness of rehabilitation.

People expect equipment. When we are seen as providing equipment, we are providing something. It's a visible thing (Therapist, P5).

Giving therapeutic equipment was valued highly by all participants, who linked equipment with improvement in function, while also providing visibility of rehabilitation occurring. Adaptive equipment (such as wheelchairs, toilet frames) was also a tangible gift (ie a visible way of giving) which was deemed to be culturally important in all community relationships.

Without equipment there is no independence (Therapist, P9)

Discussion was held around the perceived low expectation by patients for physical improvement. It was strongly felt that this was linked to lack of awareness about the possible outcomes of rehabilitation due to the previous lack of any rehabilitation service. In contrast, cultural factors such as a reluctance to ask for assistance or stoicism regarding illness events were considered to be minor reasons for low expectations of improvement. Increasing the visibility of rehabilitation and the work of Te Vaerua was viewed as key to changing these perspectives on disability and the possible life that people may live with impairments.

I think there has been a low expectation. I think that people do want to improve, once they realise that someone is actually going to help them. You know, there is a low expectation about getting better, but when someone actually goes and sees them, and says 'we can actually improve on these areas' then they want it - they want to improve (Therapist, P9).

\section{Rehabilitation has heart}

The theme of giving was paramount to understanding rehabilitation, with 'having the right attitude and heart' (Board Member, P1) being vitally important to provision of quality services. This theme was presented in interlinked ideas of relationship and generosity. Personal, high-trust relationships between the patient, their family, and the individual therapist were considered vital to successful rehabilitation. 
I think that relationship is a really important part of any health professional role. The links that you make with people that can be the main - if you don't have the relationship, there isn't going to be a good outcome (Therapist P5).

How therapists were viewed by the community depended on how able they were to establish trusted relationships with patients, families and referrers. Taking time to establish an initial relationship; being culturally aware, such as removing shoes outside the house; smiling; use of Māori language; maintaining confidentiality; accepting food and presence in the wider community (such as children in local schools, attendance at church) were important factors that were given as examples of ways relationships could be strengthened.

Relationship building was not only considered important on an individual level - it also related to the service as a whole. People were considered more likely to engage with a service that was seen to be part of the community for an extended time, rather than a short term project.

Once they realise that you are there, for the long run, that you are going to be a constant, being there, then they will commit (Funder, P6).

An equally important aspect of Cook Islands Māori tradition is the concept of 'manaaki ki te tangata' (being generous towards others), where 'manaaki' speaks of looking after or care, but also of respect and kindness. From a Cook Islands perspective, generosity is viewed as an exchange of gifts rather than as one party being the philanthropic benefactor. The fundamental concept of generosity underlies the relational heart of rehabilitation provided by Te Vaerua. Indeed, the term Te Vaerua was translated by participants in the study as meaning 'a spirit of giving without expecting return'.

Rehabilitation gives hope

Hope was a major theme regarding rehabilitation expressed by Te Vaerua, with hope considered a vital part of rehabilitation. Participants in this study referred to hope for the recovery of the individual, their family, and their community, but also to the importance of giving hope to people with disabilities in the community by creating opportunities and expectations through changing the perceptions of society.

Hope was expressed in a number of ways: early intervention in order to support families acutely, provision of tangible services such as equipment, visibility in the community to aid accessibility, provision of rehabilitation on Rarotonga (rather than New Zealand), prompt responses to community referrals, and the sharing of positive outcomes by way of case studies or the employment of people with disabilities.

I needed somebody to show me the possibility. Perfect. And that is it - it is the hope, the possibility of being better than what you are right now after this accident (Board member, P8).

\section{Table 2: Overview of themes related to the concept of rehabilitation in Te Vaerua}

Central concept: Ko te iti tangata te mea maata. "People are the most important thing"

\begin{tabular}{ll}
\hline Main themes & Subordinate themes \\
\hline Rehabilitation is available & Rehabilitation is: \\
& - Local (ie based in Rarotonga) \\
& - Visible (ie to the community; to funders) \\
& - Practical (ie everyday solutions for everyday needs; solution focused) \\
Rehabilitation has 'heart' & Rehabilitation is: \\
& - Relational (ie interpersonal skill are more vital than clinical skills; personal stories and self- \\
& - sharing is valued) \\
& Renerous (manaki ki te tangata - be generous) \\
Rehabilitation gives hope & Reduces family burden \\
& - Shows possibilities and build awareness \\
\hline
\end{tabular}

Actions occurring as part of the study

Outcomes and action points arising from this research were an intrinsic and ongoing part of service delivery, and implementation extended past the involvement of the research timeframe, overlapping with non-research activities implemented by Te Vaerua. One action arising from this study was presentation of the preliminary findings to the Ministry of Health to support Te Vaerua's objective of enhancing their visibility. Other ideas arising from the study were considered valuable but were not prioritised to be implemented, or were completed by members of Te Vaerua outside of the participant group and outside of the timeframe of the study. No participant was present in every discussion or focus group, which limited follow through of suggested actions arising from some discussions. An example of this was identification of the data collection as a priority activity for the organisation. Data 
collection was considered highly important for: 1) identifying the extent of rehabilitation need on the islands, 2) long term strategic planning to better meet identified needs, 3) providing service delivery feedback to funders, and 4) validating how Te Vaerua was adding value to people's lives. Te Vaerua identified that improved links with other healthcare providers in the Cook Islands would improve data collection and should assist overall provision of services to people with disabilities. However, this action was not implemented within the timeframe of the study.

\section{DISCUSSION}

Findings indicate that rehabilitation in the Cook Islands is an expression of the value of people and communities. Te Vaerua is primarily concerned with the wellbeing of the individuals and families within the community, and views rehabilitation as a valuable form of support. Strong relationships at all levels of service function, between individuals and with the wider community, are seen as vital to offering rehabilitation. The result of successful relationships is rehabilitation that offers pragmatic solutions and gives hope to families.

Past research suggests that ideas of relationship building and offering hope are not foreign concepts to "Western" healthcare provision where hope is considered an important factor for long term outcomes and a source of motivation and support for individuals and families through recovery (Bright 2011, Bright et al 2011, Levack et al 2009). Similarly, relationships or therapeutic alliances are seen to have a positive influence on rehabilitation outcomes (Fadyl et al 2011, Hall et al 2010, Muller et al 2015). However, in "Western" rehabilitation literature, both relationships and hope tend to take a back seat to the more commonly voiced goal of gaining personal independence, and are seldom seen as fundamental to the framework of service provision

Findings from this study support the notion that CBR is a useful framework for rehabilitation services in emerging nations one which allows expression of rehabilitation to reflect local and cultural values. Contracted specialists in nations like the Cook Islands need to explore their own culturally embedded understandings and reflect on how these might influence practice (Papps and Ramsden 1996), and ways to make these explicit rather than assumed for those they partner with. As well as being mindful of cultural safety, contracted specialists should also be aware of local expectations when working with or establishing rehabilitation services. The study findings indicate that it may not be sufficient to simply 'ask' locals what they would want rehabilitation services to provide as culturally embedded understandings must be recognised before they can be articulated. It is therefore important that studies or projects which set out to gain a perspective of what an emerging rehabilitation service should be like within a setting do not simply ask participants for their opinion. Reflexive, critical understanding is at the heart of cultural safety, and provides a basis for development and discussion of shared understanding (Richardson 2004, Wepa 2015).

In this study there was no single understanding or expectation of what rehabilitation should be like among Te Vaerua board members and other stakeholders; instead there was a reliance on the 'expert' understandings of "Western" health professionals to guide service development. Given the differences in cultural understandings of what is valued in rehabilitation that were revealed by this study, "Western" health professionals' development of services is problematic. The emphasis on relationships in providing rehabilitation services has implications for short-term and externally-funded projects. Time and activities to establish relationships should be included within project timeframes in order to achieve desired outcomes.

This study looked at values and meanings of rehabilitation held by one CBR provider in the Cook Islands. These findings may not be transferrable to other countries in the wider Pacific region. However given the value Pacific Island nations place on culture and strong relationships, the experiences reported in this paper should be pertinent to health professionals working to develop and deliver services in the Pacific.

While PAR appears to be a valid option for cross cultural research in the Pacific, particularly for CBR projects which have alignment of ideology, time limitations, participant availability and gaining a shared vision for the research are significant challenges that researchers face using these methods. Other publications have suggested that member participation is an uncontrollable but vital factor for both PAR and CBR (Kuipers et al 2008). Greenwood et al (1993) stated that it is impossible to "impose participation on research processes" (p.175) and therefore PAR is an emergent and organic process. The snowball sampling used in this study and other commitments of participants meant that no participant was involved throughout the full research journey in all aspects of the study. This slowed implementation of agreed or suggested actions.

Another limitation of this particular study is that no data were directly gathered from service users. Although patient and community viewpoints were identified by participants as valuable, there was no clear avenue for allowing this data collection to occur within the timeframe of the study, or in the role of the researcher as it was initially agreed. A study of longer duration, that provided more time for relationship building with potential study participants, may have allowed this to occur more successfully. This is an important, but challenging, area of work for future studies. One particular study method that might be of use in future studies in this regard is PhotoVoice (Wang and Burris 1997). PhotoVoice is a PAR method that involves photography, social action, and collaborative story-telling to create social change. It has been successfully used to explore health and disability issues from community perspectives in other developing economies around the world (Adekeye et al 2014, Lal et al 2012, Whitzman et al 2013). It is likely to also add value to understandings of disability and rehabilitation in the Pacific region.

\section{CONCLUSION}

The themes identified in this study provide insights into the provision of rehabilitation in the Cook Islands. While the beliefs and values of the Te Vaerua group are their own, and are not necessarily applicable to all settings, these findings provide guidance for the development of other rehabilitation services in similar settings, such as other Pacific Island nations, 
or to "Western" therapists providing services in this region. Funding of PAR research is inherently valuable (economically and qualitatively) in poorly resourced countries when the PAR process itself creates the changes required. Exploration of values and expectations of rehabilitation would be useful for other small Pacific nations as they embark on CBR projects in their communities.

\section{KEY POINTS}

1. Concepts of cultural safety underpin success of implementing rehabilitation services in cross cultural settings.

2. Strong relationships between providers and the local community are essential to successfully implement PAR and CBR.

3. Rehabilitation in the Cook Islands sits within a broader social context towards enhancing community, family and economic engagement.

\section{PERMISSIONS}

This study was reviewed and approved by the University of Otago Rehabilitation Human Ethics Committee (13/185) and the Health Research Committee of the Cook Islands National Research Council. Informed consent was gained from participants.

\section{DISCLOSURES}

No funding was gained for this study, which formed part of the requirements of a Masters in Rehabilitation for the primary author. No conflicts of interest are present.

The authors would like to thank Te Vaerua and all participants in this study for their contribution of their most valuable time and experience to this work. Thanks also to Pareina Mokoroa Tangata for her expertise and experience.

\section{ADDRESS FOR CORRESPONDENCE}

Rebecca Washbourn, PO Box 32004, Christchurch, 8147

Email: rebecca.washbourn@student.otago.ac.nz

\section{REFERENCES}

Adams-Smith PH (2002) An exploration of issues of primary health services for Taranaki te Atiawa children based on the expectations and perceptions of their female caregivers. (Masters of Art (Nursing)) Victoria University. Retrieved from http://hdl.handle.net/10063/75.

Adekeye O, Kimbrough J, Obafemi B, Strack RW (2014) Health literacy from the perspective of African immigrant youth and elderly: A photovoice project. Journal of Health Care for the Poor and Underserved 25: 17301747.

Balasubramanian MM, Dhanesh K, Amarnath A (2012) Functional independence and quality of life for persons with locomotor disabilities in institutional based rehabilitation and community based rehabilitation: A comparative study. Disability, CBR and Inclusive Development 23(3): 150155. doi:10.5463/dcid.v23i3.147

Biggeri M, Deepak S, Mauro V, Trani J-F, Kumar J, Ramasamy P (2014) Do community-based rehabilitation programmes promote the participation of persons with disabilities? A case control study from Mandya District, in India. Disability \& Rehabilitation 36(18): 1508-1517. doi:10.3109/096382 88.2013 .823244
Bowers B, Kuipers P, Dorsett P (2015) A 10 year literature review of the impact of community based rehabilitation. Disability, CBR and Inclusive Development 26(2): 16

Bradbury H, Reason P (2008) Issues and choice points for improving the quality of action research. In Minkler M, Baden AC (Eds) Community Based Participatory Research for Health: From Process to Outcomes (2nd edn). San Francisco: John Wiley and Sons, pp 225-242.

Bright F (2011) Exploring hope in people with aphasia following stroke. (Masters of Health Science), Auckland University of Technology. Retrieved from http://aut.researchgateway.ac.nz/bitstream/handle/10292/2467/ BrightF.pdf? sequence=3\&isAllowed=y .

Bright F, Kayes N, McCann C, McPherson K (2011) Understanding hope after stroke: A systematic review of the literature using concept analysis. Topics in Stroke Rehabilitation 18(5): 490-508.

Deepak S, Kumar J, Ramasamy P, Griffo G (2014) An emancipatory research on CBR and the barriers faced by persons with disabilities. Disability \& Rehabilitation 36(18): 1502-1507. doi:10.3109/09638288.2013.800914.

Durie M (1994) Maori perspectives on health and illness. In Trlin AD, Walton JA, Spicer J (Eds) Social Dimensions of Health and Disease : New Zealand Perspectives. Palmerston North: Dunmore Press, pp 194-203.

Fadyl JK, McPherson KM, Kayes NM (2011) Perspectives on quality of care for people who experience disability. BMJ Quality and Safety 20(1): 87-95.

Fitzgerald MH (1992) Multicultural clinical interactions. Journal of Rehabilitation 58(2): 38-42.

Frisby W, Reid CJ, Millar S, Hoeber L (2005) Putting "participatory" into participatory forms of action research. Journal of Sport Management 19(4): 367-386.

Grandisson M, Thibeault R, Hébert M, Cameron D (2016) Expert consensus on best evaluative practices in community-based rehabilitation. Disability and Rehabilitation 38(5): 499-510. doi:10.3109/09638288.2015.104403 0 .

Greenwood DJ, Whyte WF, Harkavy I (1993) Participatory action research as a process and as a goal. Human Relations 46(2): 175-192. doi:10.1177/001872679304600203.

Hall AM, Ferreira PH, Maher CG, Latimer J, Ferreira ML (2010) The influence of the therapist-patient relationship on treatment outcome in physical rehabilitation: a systematic review. Physical Therapy 90(8): 1-12.

Hughes I (2008) Action research in healthcare. In Reason P, Bradbury H (Eds) The SAGE Handbook of Action Research: participative inquiry and practice (2nd edn). Los Angeles: Sage, pp 379-393.

lemmi V, Gibson L, Blanchet K, Kumar KS, Rath S, Hartley S, Murthy GV, Patel V, Weber J, Kuper H (2015) Community-based rehabilitation for people with disabilities in low- and middle-income countries: a systematic review. Campbell Systematic Reviews 15. doi:10.4073/csr.2015.15.

International Labour Organization, United Nations Educational Scientific and Cultural Organization, World Health Organization (2004) CBR : A strategy for rehabilitation, equalization of opportunities, poverty reduction and social inclusion of people with disabilities : joint position paper. Retrieved from http://whqlibdoc.who.int/publications/2004/9241592389_eng. pdfhttp://whqlibdoc.who.int/publications/2004/9241592389_eng.pdf [Accessed 8 September, 2013].

Khasnabis C, Motsch K, Achu K (2010) Community-Based Rehabilitation: CBR Guidelines. Retrieved from http://www.ncbi.nlm.nih.gov/books/ NBK310940/.

Kuipers P, Allen O (2004) Preliminary guidelines for the implementation of community based rehabilitation (CBR) approaches in rural, remote and indigenous communities in Australia. Rural and remote health, 4, 291. http://rrh.deakin.edu.au Retrieved from http://rrh.deakin.edu.au.

Kuipers P, Wirz S, Hartley S (2008) Systematic synthesis of community-based rehabilitation (CBR) project evaluation reports for evidence-based policy: A proof-of-concept study. BMC International Health and Human Rights 8(3). doi:10.1186/1472-698X-8-3. 
Lal S, Jarus T, Suto MJ (2012) A scoping review of the photovoice method: Implications for occupational therapy research. Canadian Journal of Occupational Therapy 79(3): 181-190.

Levack WM, Siegert RJ, Dean SG, McPherson KM (2009) Goal planning for adults with acquired brain injury: How clinicians talk about involving family. Brain Injury 23(3): 192-202. doi:10.1080/02699050802695582.

Madden RH, Dune T, Lukersmith S, Hartley S, Kuipers P, Gargett A, Llewellyn $G$ (2013) The relevance of the international classification of functioning, disability and health (ICF) in monitoring and evaluating community-based rehabilitation (CBR). Disability \& Rehabilitation 36: 826-837.

Maiter S, Simich L, Jacobson N, Wise J (2008) Reciprocity: An ethic for community-based participatory action research. Action Research 6(3): $305-$ 325. doi:10.1177/1476750307083720.

Mclntyre A (2008) Participatory action research. Los Angeles: Sage Publications.

McTaggart R (1991) Principles for participatory action research. Adult Education Quarterly 41(3): 168-187. doi:10.1177/00018481910410030 03.

Ministry of Finance and Economic Management (2012) Cook Islands census of population and dwellings 2011. Rarotonga: Ministry of Finance and Economic Management.

Mpofu E (2001) Rehabilitation an international perspective: A Zimbabwean experience. Disability and Rehabilitation 23(11): 481-489. doi:10.1080/09638280010008889.

Muller I, Kirby S, Yardley L (2015) The therapeutic relationship in telephonedelivered support for people undertaking rehabilitation: a mixed-methods interaction analysis. Disability \& Rehabilitation 37(12): 1060-1065 1066p doi:10.3109/09638288.2014.955134

Nuri RP, Hoque T, Waldron SM, Akand MK (2012) Impact assessment of a vocational training program for persons with disabilities in Bangladesh. Disability, CBR and Inclusive Development 23(3): 76-89. doi:10.5463/dcid. v23i3.81.

O'Toole B (1987) Community based rehabilitation (CBR): Problems and possibilities. European journal of special needs education 2(3): 177-190.
Papps E, Ramsden I (1996) Cultural safety in nursing: The New Zealand experience. International Journal for Quality in Health Care 85(5): 491497.

Richardson S (2004) Aoteaoroa/New Zealand nursing: From eugenics to cultural safety. Nursing Inquiry 11(1): 35-42.

Roberts LW (2013) Community-based participatory research for improved mental healthcare. A manual for clinicians and researchers edn). New York: Springer Science+Business Media.

Sadler GR, Lee H, Lim RS, Fullerton J (2010) Recruitment of hard-to-reach population subgroups via adaptations of the snowball sampling strategy. Nursing \& Health Sciences 12(3): 369-374.

Shakespeare T, Officer A (2014) Breaking the barriers, filling the gaps. Disability and Rehabilitation 36(18): 1487-1488. doi:10.3109/09638288.2 013.878552 .

Somekh B (2005) Action Research : A Methodology for Change and Development. Cochrane Database of Systematic.

Spencer L, Ritchie J, O'Connor W (2003) Analysis: Practices, Principles and Processes. In Ritchie J, Lewis J (Eds) Qualitative research practice: A guide for social science students and researchers edn). London: Sage Publications, pp 199-218.

Thomas M, Thomas MJ (1999) Influence of cultural factors on disability and rehabilitation in developing countries. Asia Pacific Disability Rehabilitation Journal 10(2): 44-46.

Wang C, Burris MA (1997) Photovoice: Concept, methodology, and use for participatory needs assessment. Health Education \& Behavior 24: 369-387.

Wepa D (2015) Cultural safety in Aotearoa New Zealand (2nd edn). Melbourne: Cambridge University Press.

Whitzman C, James K, Poweseu I (2013) Travelling together: participatory research methods for disability inclusive road development in Papua New Guinea. Journal of Transport Geography 26: 65-71.

Yuenwah S (2012). Relevance of CBR for the Asia-Pacific Region. Disability, CBR and Inclusive Development, 23(1), 7. doi:10.5463/dcid.v23i1.114. 